\title{
Laboratory Experiment on Enhanced Oil Recovery Using Nanoparticles (NPs) and Permeability Alteration Due to Their Retention in Porous Media
}

\section{Odo Jude Emeka, Ohia Princewill Nnaemeka, Nwogu Ngozi, Oguamah Ifeanyi, Ekwueme Stanley, Ezeh Samuel Chukwudiegwu}

Department of Petroleum, Federal University of Technology, Owerri, Nigeria

Email address:

jude.odo@futo.edu.ng (O. J. Emeka), princepetra@yahoo.com (O. P. Nnaemeka),nwogungozi2@gmail.com (N. Ngozi),

Uchelex@gmail.com (O. Ifeanyi),stanleyekwueme@yahoo.com (E. Stanley), samuelezeh87@gmail.com (E. S. Chukwudiegwu)

\section{To cite this article:}

Odo Jude Emeka, Ohia Princewill Nnaemeka, Nwogu Ngozi, Oguamah Ifeanyi, Ekwueme Stanley, Ezeh Samuel Chukwudiegwu. Laboratory Experiment on Enhanced Oil Recovery Using Nanoparticles (NPs) and Permeability Alteration Due to Their Retention in Porous Media. American Journal of Engineering and Technology Management. Vol. 5, No. 1, 2020, pp. 18-26. doi: 10.11648/j.ajetm.20200501.13

Received: January 14, 2020; Accepted: February 10, 2020; Published: March 17, 2020

\begin{abstract}
After secondary flooding, the process of injecting chemicals such as Nanoparticles into the reservoir in order to release and produce the trapped oil in that reservoir is called chemical flooding enhanced oil recovery (CEOR). The trapped oil is due to some forces such as viscous, gravity and capillary forces. Several reservoir problems have been solved with the use of Nanoparticles but the disadvantage is the retention of these Nanoparticles in the pore spaces which can cause pore blockage of reservoir rock and reduce its permeability. The primary aim of oil industry is to find the effect of these nanoparticles on oil recovery. In this work, some types of nanoparticles were selected for sand-pack oil displacement flood test. These Nanoparticles are Magnesium oxide $(\mathrm{MgO})$, Aluminum oxide $\left(\mathrm{Al}_{2} \mathrm{O}_{3}\right)$ and silicon oxide $\left(\mathrm{SiO}_{2}\right)$. They were selected because of their effect to improve oil recovery. They were used to conduct enhanced oil recovery and to evaluate the effect of their retention in porous media at $45^{\circ} \mathrm{C}$ and $3000-3500$ Pisa. The Nanoparticles were dispersed in brine. The control experiment and the experiment when Nanoparticles were dispersed in brine were the two set of experiment conducted. The control experiment was used as a bench mark to compare the effect of nanoparticles on oil recovery. From the results obtained from this experiment, Aluminum oxide $\left(\mathrm{Al}_{2} \mathrm{O}_{3}\right)$ was the best performed Nanoparticle after enhanced oil recovery flooding process. Nanoparticles were used to prepare the nanofluids used for tertiary recovery. Nanofluids used to displace oil yield better results but when only brine was used, the recovery was low compared with that of nanoparticles. Increase in nanoparticle concentration increases oil recovery. There was a decrease in permeability of the reservoir rock. Increase in nanoparticles concentration increases the total cost of preparing the nanofluid. The decrease in permeability is caused by pore blockage due to nanoparticles retention in porous media. Only $\mathrm{Al}_{2} \mathrm{O}_{3}$ at $0.2 \%$ wt is economical feasible compared with other nanoparticles. The ability of nanoparticles to alter certain factors in the formation and in oil properties can be taken as advantage on oil recovery.
\end{abstract}

Keywords: Nanopartcles, Retention, Alteration, Nanofluids, Enhanced Oil Recovery

\section{Introduction}

Most emphasis was laid on enhanced oil recovery (EOR) methods because two-third of the original oil in placed is left unrecovered when most of the oil field in the world is approaching maturity. The recovery efficiency of the oil can be improved by EOR processes. About $37 \%$ of the original oil in placed can be recovered by CEOR. There are three phases or stages of hydrocarbon recovery namely: primary, secondary and tertiary (EOR) stages. Primary recovery method means using energy sources that naturally exist in the reservoir to produce oil. The energy sources include natural water drive, gas cap drive, solution-gas drive, fluid expansion etc. The reservoir pressure decreases as oil production continues until a point where the pressure that exists in the reservoir is not enough for the production of the oil to the 
surface. At that condition the pressure of the reservoir can be maintain in order to displace oil toward the production well by injecting water or gas into the reservoir. This stage of oil recovery is referred to as secondary or water flooding recovery method. After the secondary flooding method, due to the viscosity of the water is less than that of oil, part of the crude oil that cannot be produce remains as a residue and trapped in the reservoir, and at that moment secondary recovery method is no longer effective, EOR is mostly introduced.

To release and produce extra trapped or residual crude oil from the reservoir with the use of other recovery techniques such as chemical flooding, thermal flooding and gas flooding methods beyond that recoverable by secondary recovery methods is called tertiary recovery methods or Enhanced Oil Recovery [12]. These methods can be categorized into thermal, gas and chemical recovery methods. Injection steam into the heavy viscous oil reservoir to lower the viscosity of the oil and improve its ability to flow through the reservoir to the surface by changing its physical properties such as density and viscosity is called thermal recovery method. Non-hydrocarbon gases such as nitrogen and carbon dioxide and hydrocarbon gases such as methane, propane or natural gases are injected into the reservoir in order to improve oil flow rate or increase its recovery by lowering or decreasing its viscosity is called gas injection methods. Among the three EOR methods of oil recovery, literatures showed that thermal techniques were more common EOR method used. But on large scale projects, chemical methods such as alkaline flooding, surfactant flooding, polymer flooding, surfactantpolymer injection mixtures and alkaline-surfactant-polymer injection mixtures are more widely used. These CEOR methods involve mixing chemicals in water prior to injection. Therefore, polymers, surfactants, alkalis and formulated mixtures are major chemicals used in Chemical Enhanced Oil Recovery.

Reduction in interfacial tension between formation water and oil, improve in sweep efficiency, increase in viscosity of formation water decrease the capillary pressure, wettability alteration of the reservoir rock, mobility ratio reduction between formation water and oil, capillary pressure reduction are the mechanism through which chemical flooding increase oil recovery [13].

The use of polymer to release and produce extra oil from the reservoir is called polymer flooding. In chemical enhanced oil recovery methods, polymer flooding is most commonly used. The main purpose of polymer flooding is to change the ratio of the displacing fluid and displaced fluid to a favorable number (value less than 1), so that the displacing fluid will not bypass the displaced fluid [12]. This method is called mobility control and it improves sweep efficiency.

Residual and trapped oil in the reservoir can be recovered by lowering or reducing the interfacial tension between formation water and oil and decreasing the capillary pressure in porous media. This method of CEOR is called surfactant flooding. Reduction of interfacial tension between formation water and oil, decreasing the capillary pressure in the porous media and altering the wettability of formation rock from oilwet to neutral to water-wet are the main purpose of surfactant flooding, but its high cost and adsorption to rock surface are the disadvantages of using surfactants [13].

In overall summary, less than $30 \%$ of the oil can be recover with primary recovery method, about $30-50 \%$ can be recovered with secondary recovery technique whereas depending on the type of crude oil and reservoir, tertiary recovery methods (EOR) can recovers greater than 50 to $80 \%$ [13].

In oil and gas industry, the three traditional enhanced oil recovery mentioned above can be used in combined form but due to challenges facing the traditional enhanced oil recovery processes such as high mobility ratio of injected gas and oil which causes the gas to penetrates quickly through the reservoirs from the injection wells to the producing wells which results to a large amount of residual oil remaining unrecovered in reservoirs, fingering and early gas breakthrough, and also high cost of chemicals, possible formation damage and loss of chemicals hinders the use of traditional enhanced oil recovery.

To carry out any enhanced oil recovery processes in oil industry, petroleum engineer has searched for an alternative ways to solve these problems. More efficient, less expensive and environmentally friendliness are greatly needed in oilfield.

\section{Literature Review}

Nanotechnology has the possibilities to solve problems in the oil and gas industry. The introduction of nanoparticles into the formation has altered certain factors in the formation and in oil properties which makes it to be commonly used to enhanced oil recovery. They are particles with size ranges from $1 \mathrm{~nm}-100 \mathrm{~nm}$. Its application in petroleum industry has become known to petroleum engineers. Nanotechnology is used in oil and gas industry to recover more trapped in the reservoir. Nanotechnology enhanced oil recovery by reducing the interfacial tension between oil and water interface, alter the wettability of rock surface and improve the mobility ratio (i.e., increasing the viscosity of the injection fluid (water) and decreasing the viscosity of the oil phase) [2]. NPs used for enhanced oil recovery agents showed some important and useful characteristics when compared to the injected fluid (gas, water and chemical) used in traditional enhanced oil recovery processes. Their useful characteristics are: (1). ultra-small size - this ultra-small size makes the NPs to penetrate into some pores where traditional injection fluids (polymers, surfactant etc) are unable to without much retention and pore plugging. The retention and pore blockage are important factors to consider in EOR and they can result to reduction in formation permeability and increase the injection cost. (2). Low cost - in oil industry, injection cost is one concern of using chemical enhanced oil recovery processes. Nanoparticles can be widely used in oil industry for enhanced oil recovery processes because their price is cheaper than the traditional chemical EOR. (3). 
Environmental friendliness - Nanoparticles used today for any enhanced oil recovery process are environmentally friendly materials compared to the traditional chemical enhanced oil recovery. They do not cause harmful effect on living organisms, human health etc.

In this study, metal oxide nanofluids such as aluminum oxide, silicon oxide, and magnesium oxide were used for experimental study on permeability alteration due to their retention in porous media. A nanofluid is simply defined as a base fluid (brine, oil, ethanol, gas etc) with nanoparticles of size less than $100 \mathrm{~nm}$. Mechanisms of nanofluids include - wettability alteration, interfacial tension reduction, mobility ratiocontrol, pore throat or cannelplugging etc. Oil recovery is affected by an important factor known as wettability. Amott test method, core displacement test and contact angle method are the three experimental methods currently used for wettability measurement. Contact angle method is the most widely used amongst the three methods [6]. The contact angle method can be divided into - waterwet formations (contact angle $<90^{\circ}$ ); oil-wet formations (contact angle $>90^{\circ}$ ) and intermediately-wet formations (contact angle $=90^{\circ}$ ) [6], [2]. It has been reported that intermediately-wet formations produce better than waterwet formations, while water-wet formations produce better than oil-wet formations [3]. Strong effects of nanoparticles on wettability alteration have been identified by many researchers in recent years. It has been proven as potential agents to alter the wettability of a formation. It has been reported that zirconium oxide $\left(\mathrm{ZrO}_{2}\right)$ nanofluid has the ability of altering the wettability of carbonate rock from strongly oil-wet condition to the strongly water-wet condition [2]. It has also been reported that aluminum oxide $\left(\mathrm{Al}_{2} \mathrm{O}_{3}\right)$ nanofluid has the ability to alter the wettability in carbonate rock from oil-wet to water-wet and increase the oil recovery by about $11.25 \%$ [1]. On the performance of wettability of limestone rock, the effect of zirconium oxide and nicke (ii) oxide $(\mathrm{NiO})$ nanofluids were investigated and from the result, better recovery efficiency was observed with zirconium oxide in changing the strongly oil-wet $(\Theta=$ $\left.152^{0}\right)$ to strongly water-wet $\left(\Theta=44^{0}\right)$. Also at concentration of $0.05 \mathrm{wt} \%$ nickel (ii) oxide changed wettability to an intermediate wet condition $\left(\Theta=86^{\circ}\right)$ [9], [7]. On Berea sandstone core, aluminum oxide, $\mathrm{SiO}_{2}$ and titanium oxide $\left(\mathrm{TiO}_{2}\right)$ nanofluids were used for wettability alteration and the result shows about $5-7 \%$ increase in recovery by titanium oxide [2]. Nanoparticles concentration, nature of the oil, nature of the reservoir and types of the nanofluids or nanoparticles are the several factors that influence the success of wettability using nanofluids. Silicon oxidenanofluid is more effective in altering the wettability of light oil than heavy oil [2]. Increase in zirconium oxide concentration increases the recovery of heavy oil [2]. To determine the types of nanofluids to be used, nature of the reservoir plays an important role. Example, for changing wettability of sandstone rocks, aluminum oxide, silicon oxide and iron (ii) oxide $\left(\mathrm{Fe}_{2} \mathrm{O}_{3}\right)$ nanofluids are effective while Zirconium dioxide $\left(\mathrm{ZrO}_{2}\right)$ and nickel oxide $(\mathrm{NiO})$ nanofluids are effective for limestone formation. But Zirconium dioxide $\left(\mathrm{ZrO}_{2}\right)$ performed better than silicon oxide $\left(\mathrm{SiO}_{2}\right)$ and aluminum oxide $\left(\mathrm{Al}_{2} \mathrm{O}_{3}\right)$ nanofluids and it also exhibit a better wettability modifier than nickel oxide (NiO) nanofluid.

It is necessary to obtain interfacial tension between oil and formation water in enhanced oil recovery processes, because it is one of the main parameters that determine fluids distribution and movement in porous media and also one of the main mechanisms for nanofluid flooding in enhanced oil recovery process [2]. Reduction in permeability of reservoir rock due to high adsorption of nanoparticles is the main reason for interfacial tension reduction. Interfacial tension is sensitive to nanofluid concentration [6]. Pendant drop method is usually used to measure the interfacial tension between crude oil and nanofluid. It has been reported by many literatures that interfacial tension can be greatly reduced when nanoparticles are added to displacing fluid [9]. Depending on the concentration of the NPs dispersed in nanofluid, these nanoparticles form a layer in the interface between crude oil and formation water, and this layer yields low interfacial tension between the two phases. Interfacial tension between synthetic oil and nanofluid was measured using pendant drop method, and from the result, interfacial tension was reduced from $14.7 \mathrm{mN} / \mathrm{m}$ to $9.3 \mathrm{mN} / \mathrm{m}$ by adding nanoparticles into the brine solution. In addition to this, interfacial tension can be further reduced from $9.3 \mathrm{mN} / \mathrm{m}$ to $5.2 \mathrm{mN} / \mathrm{m}$ by increasing the concentration of the nanofluid from $0.01 \mathrm{wt} \%$ to $0.05 \mathrm{wt} \%$ [6]. After an experiment to compare the effects of aluminum oxide $\left(\mathrm{Al}_{2} \mathrm{O}_{3}\right)$ and silicon oxide $\left(\mathrm{SiO}_{2}\right)$ nanofluids on interfacial tension reduction at ambient conditions, it was reported that $\mathrm{SiO}_{2}$ nanofluid had a lower IFT value when added into brine solution than $\mathrm{Al}_{2} \mathrm{O}_{3}$, which means that it had the potential to produce more oil than $\mathrm{Al}_{2} \mathrm{O}_{3}$ [6]. Three nanofluids $\left(\mathrm{SiO}_{2}, \mathrm{Al}_{2} \mathrm{O}_{3}\right.$ and $\mathrm{NiO})$ where compared for their ability to reduce interfacial tension, from the experiment, $\mathrm{SiO}_{2} \mathrm{NPs}$ had the lowest interfacial tension value [6]. $\mathrm{SiO}_{2}$ has more effect on interfacial tension reduction than wettability alteration [6]. In conclusion, IFT decreases as nanofluid concentration increases [6].

Mobility ratio can be improve or control by reducing the viscosity of the oil when nanoparticles are added to the displacing fluid. Outside the reservoir formation and under surface condition, it has been discovered from experiment that $\mathrm{Al}_{2} \mathrm{O}_{3}$ nanofluid is effective in reducing the viscosity of oil (especially heavy oil) which hinders recovery [3]. It has been studied that $\mathrm{Fe}_{2} \mathrm{O}_{3}$ nanofluid has the ability to increase the viscosity of displacing fluid leading to increase in sweep efficiency [3]. In terms of viscosity reduction, aluminum oxide produces highest recovery in sandstone rocks while dispersed in diesel [3]. Also, in terms of viscosity reduction, it produces oil lighter than injected oil [10], [3]. It has been reported that aluminum oxide nanoparticles is a known agent used to reduce the viscosity of oil [3]. Type of nanoparticle, temperature, shear rate and nanoparticle concentration affect 
the viscosity of nanofluids. For instance: increase in concentration of nanoparticle and brine salinities increases the viscosity of nanofluids. The viscosity of aluminum oxide nanofluid is lower than that of silicon oxide nanofluid at the same concentration. Decrease in shear rate, increases the viscosity of silicon oxide nanofluid. At low temperature, the increasing rate of viscosity of silicon oxide nanofluid is higher than at high temperature. During core flooding test, magnesium oxide nanoparticle results to permeability problem in sandstone rocks caused by pore blockage while dispersed in brine or ethanol or distilled water. Therefore, it is a weak recovery agent for enhanced oil recovery sandstone rocks [6], [5]. To control fines migration in reservoirs, magnesium Oxide nanaoparticle has been reported to yield good result [3]. Also magnesium Oxide nanoparticle can reduce oil viscosity when the rock sample is soaked in ethanol [8].

It has been reported from many literatures that in nanofluid injection, displacement efficiency and recovery factor increases with increase in temperature. In addition, increase in temperature might result to interfacial tension reduction since the molecular interaction between the liquid are weaker. Since Brownian motions are one of energies that drive oil displacement due to nanoparticle, its force will increase as the temperature increases. Nanofluid injection should be valid at higher temperature before applying them in field condition since the reservoir temperature is much higher than the surface conditions. The lower the salinity of fluid, the more effective it displaces oil. Therefore formation water with a low salinity is more effective in displacing oil than the one with high salinity [3]. The larger the rock grains, the lower the surface area per unit bulk volume, since the surface area of the porous media depends on grain size. Therefore, reduction in surface area per unit bulk volume decreases the retention of the NPs on the rock [4]. The larger grain size exhibit a lower porosity than the smaller grain size. To enhance oil recovery, the concentration of the NP in the displacing fluid is one of the major factors that affect the nanofluid injection into porous media. Though increase in nanoparticle concentration helps in the enhancement of oil displacement efficiency, but oil recovery decreases due to pore throat blockage when the nanoparticle concentration is increased above or beyond optimum concentration (around $3 \mathrm{wt} . \%)$ and this pore blockage will reduce the porosity and absolute permeability [4]. For better understanding of nanofluid effects on permeability, a comprehensive study and understanding the retention of NPs after nanofluid injection is one of the critical issues which provides essential foundation for the benefits of NPs in enhanced oil recovery. For better understanding of nanofluid effects on permeability, a comprehensive study and understanding the retention of nanoparticles after nanofluid injection is one of the critical issues which provides essential foundation for the benefits of nanoparticles in enhanced oil recovery. Increase in injection rate makes the small water molecule to speed up faster than the nanoparticles, leaving the nanoparticle to accumulate at the pore throat. As the nanoparticle accumulates, it blocks the pore throat and thereby results to decrease in oil recovery and reduction in permeability. Furthermore, during injection, if the diameter of the injected nanoparticle is larger than pore channel that it flows through, NP will be retained and blockage will occur and this will cause permeability reduction.

\section{Experimental Description}

Materials: The materials used to conduct experiment in this work include: sand, unconsolidated sand-packs, crude oil, nanofluids, nanoparticles, aluminum foils, masking tape, industrial salt ( $\mathrm{NaCl})$, prepared laboratory brine, industrial sieve, net and distilled water.

Apparatus: the apparatus used to conduct experiment in this work include: AFS 300 core flooding system, stop watch, measuring cylinder, beaker, round bottom flask, density meter, electronic weighing balance, mechanical sieve shaker, magic stirrer, oven, thermometer, cannon viscometer bath, and viscometer tube.

The crude oil used for this experiment was supplied by Laser Engineering and Resources Consultant Limited, Rumuodara Port Harcourt, Rivers State. It can be classified as medium crude oil with viscosity of $60.2 \mathrm{cp}$, density of $0.9110 \mathrm{~g} / \mathrm{cc}$ and ${ }^{0} \mathrm{API}$ of $22.46 @ 15^{\circ} \mathrm{C}$, all at ambient temperature $\left(25.7^{\circ} \mathrm{C}\right)$. Laboratory prepared brine of $30,000 \mathrm{ppm}$ or $30 \mathrm{~g} / 1$ concentration was used. Industrial salt $(\mathrm{NaCl}-99.5 \%$ extra pure) was used to prepare the brine. Its weight is $30 \mathrm{~g}$. The salt was dissolved in $1000 \mathrm{ml}$ of distilled water. The density of the brine was $1.0167 \mathrm{~g} / \mathrm{cm}^{3}$. The sandpacks length ranges from $6.9-7.5 \mathrm{~cm}$ and its diameter ranges from $3.5-3.9 \mathrm{~cm}$ were used. The sand were washed, dried and sieved before the preparation of sand-packs. The sandpacks were used for oil displacement flood test in a horizontal direction with different concentrations; $0.2 \% \mathrm{wt}$ and $0.4 \%$ wt for aluminum oxide, silicon oxide and magnesium oxidenanoparticles respectively. Table 1 shows the rock properties used for this experiment. Three different NPs such as aluminum oxide, silicon oxide andmagnesium oxide were used for the purpose of this experiment. These enhanced oil recovery agents were dissolved in the brine using stirrer for the preparation of nanofluids used for enhanced oil recoveryprocess. Masking tape was used to label the sand-packs and different apparatus used throughout the experiment. The experiments were conducted at pressure of 3000 to $3500 \mathrm{psi}$, flow rate of $1 \mathrm{ml} / \mathrm{min}$, and at core-holder temperature of $45^{\circ} \mathrm{C}$. This is the usual pressure and temperature of most wells.

AFS300 core flooding system was the main equipment used for this experiment. The equipment is configured for liquid/liquid displacement or gas/liquid displacement under unsteady state conditions at pressure up to 10,000 psig, pore pressure up to $9,250 \mathrm{psig}$ and temperatures up to $300^{\circ} \mathrm{F}$. This equipment is divided into two parts - control unit and the oven. Density meter was used to determine the density, specific gravity and ${ }^{0}$ API gravity of the test fluid. Electronic weighing balance was used to determine the weight of the 
industrial salt, dry weight and wet weight of each sand-pack. Mechanical sieve shaker was used to shake the grain sand in order to obtain the desire fine grains needed for the sandpack preparation. Constant viscometer bath was used with viscometer tube to determine the viscosity of the test fluids. The thermometer was used to set the temperature of the viscometer bath (i.e., core holder temperature of $45^{\circ} \mathrm{C}$ and ambient temperature of $25.7^{\circ} \mathrm{C}$. Oven was used to dry the washed sand before sieving operation at $80^{\circ} \mathrm{C}$. This temperature was chosen for fast drying. Measuring cylinder was used to measure the volume of distilled water for brine preparation. Lastly, the stop watch was used to take the efflux time. The efflux time depends on the kinematic viscosity while kinematic viscosity depends on dynamic viscosity and brine density.

\section{Theory}

All the experiments were carried out at the same temperature, pressure and flow rate. In order to estimate the contribution of nanoparticles to the total recovery with respect to permeability alterations, this experiment was first conducted without the use of nanoparticles known as control experiment while other experiments were conducted with nanoparticles dispersed in brine. To evaluate the effects of nanoparticles on permeability, the permeability value for controls was determined and that of sand-packs flooded with nanoparticles was determined and the permeability alterations were evaluated. In oil displacement efficiency, fluid plays a significant role. Low salinity brine of $30 \mathrm{~g} / 1$ concentration was used to displace the oil because it displaces oil more effectively than high salinity brine. For each NP, two concentrations $(0.2 \%$ and $0.4 \%)$ were used to evaluate their effect in oil recovery. The primary objective of this project is to determine the effect of permeability alteration due to NPs retention in porous media with respect to enhanced oil recovery.

\section{Experimental Procedures}

i. Laboratory brine was prepared using industrial salt $(\mathrm{NaCl})$.

ii. Unconsolidated sand-packs were prepared using sand grains size between 60 to 250 microns. They were saturated with laboratory brine solution $(30 \mathrm{~g} / \mathrm{l})$ for three days.

iii. Rock properties such as dry weight, wet weight, pore volume, bulk volume and porosity were determined.

iv. Test fluid properties such as density, API gravity, specific gravity, kinematic and dynamic viscosity were determined.

v. Absolute permeability was determined by injecting only brine through the inlet pipe into the core-holder until a stable differential pressure across the sample was achieved.

vi. The flooding experiment began by conducting a drainage test (injecting crude oil). This displaces the laboratory brine in the sand-pack until irreducible water saturation was achieved (i.e., until no sight of water droplet through the outlet pipe into the measuring cylinder). Oil breakthrough time was recorded, as the time the first drop of oil was sighted through the outlet pipe. Also volume of water displaced which is equal OOIP was recorded.

vii. Imbibition test was conducted by injecting 10 pore volume of brine through the inlet pipe into the coreholder to displace the oil until irreducible oil saturation was achieved. From experience, 10 pore volumes is normally use for optimum recovery. Volume of oil displaced after water flooding was recorded. The time for water breakthrough was taken. Oil displacement efficiency was calculated and recorded. Note: Steps 1 to 7 were conducted only for control experiment and other experiment were performed following the same procedures above.

viii. After step seven, nanofluids were prepared and tertiary recovery method was conducted by injecting the 10PV of nanofluid through the inlet pipe into the core-holder to displace more oil. Oil recovered was recorded and oil displacement efficiency was also calculated and recorded.

ix. After which, the unconsolidated sand-pack was removed from the core-holder and weighed. Note: This process was repeated for each sand-pack and nanofluids used.

x. Lastly, permeability alterations were evaluated for each nanoparticle.

Table 1. Properties of test fluid at $0.2 \%$ wt concentration.

\begin{tabular}{llllll}
\hline Properties & Brine $(\mathbf{3 0 g ~ N a C l})$ & Brine (with 0.2\% $\left.\mathbf{A l}_{2} \mathbf{O}_{3}\right)$ & Brine (with 0.2\% MgO) & Brine (with 0.2\% SiO & Crude Oil $_{2}$ \\
\hline Density $\left(\mathrm{g} / \mathrm{cm}^{3}\right)$ & 1.0167 & 1.0171 & 1.0146 & 1.0189 & 0.9110 \\
S.G & 1.0202 & 1.0203 & 1.0178 & 1.0221 & 0.9138 \\
${ }^{\circ} \mathrm{API} @ 15^{\circ} \mathrm{C}$ & - & - & - & - & 22.46 \\
Viscosity $(\mathrm{cP})$ & 0.95 & 0.97 & 0.96 & 1.04 & 60.2 \\
\hline
\end{tabular}

Table 2. Properties of test fluid at $0.4 \%$ wt concentration.

\begin{tabular}{lllll}
\hline Properties & Brine $(\mathbf{3 0 g ~ N a C l})$ & Brine (with $\left.\mathbf{0 . 4} \% \mathbf{A l}_{2} \mathbf{O}_{3}\right)$ & Brine (with 0.4\% MgO) & Brine $($ with 0.4\% SiO $)$ \\
\hline Density $\left(\mathrm{g} / \mathrm{cm}^{3}\right)$ & 1.0167 & 1.0191 & 0.9996 & 1.0183 \\
S.G & 1.0202 & 1.0224 & 1.0028 & 1.0215 \\
${ }^{\circ}$ API @ $15^{\circ} \mathrm{C}$ & - & - & - & - \\
Viscosity $(\mathrm{cP})$ & 0.95 & 0.86 & 0.91 & 0.94 \\
\hline
\end{tabular}


Table 3. Permeability values for different nanofluids.

\begin{tabular}{llll}
\hline Nanoparticle & Absolute permeability (md) & $\begin{array}{l}\text { Effective permeability during EOR } \\
\text { assisted water flooding (md) }\end{array}$ & Difference in permeability (md) \\
\hline control & 1269 & N/A & N/A \\
$\mathrm{SiO}_{2}$ & 1211 & 356 & 855 \\
$\mathrm{Al}_{2} \mathrm{O}_{3}$ & 1214 & 729 & 485 \\
$\mathrm{MgO}$ & 911 & 250 & 661 \\
$\mathrm{SiO}_{2}$ & 729 & 405 & 324 \\
$\mathrm{Al}_{2} \mathrm{O}_{3}$ & 1197 & 399 & 798 \\
$\mathrm{MgO}$ & 729 & 258 & 471 \\
\hline
\end{tabular}

\section{Results and Discussions}

Figure 1 generally shows that, aluminum oxide $\left(\mathrm{Al}_{2} \mathrm{O}_{3}\right)$ gave the best maximum displacement efficiency followed by silicon oxide $\left(\mathrm{SiO}_{2}\right)$ nanoparticles while magnesium oxide $(\mathrm{MgO})$ nanoparticles had the lowest oil recovery factor. At $0.4 \%$ concentration, displacement efficiency of $\mathrm{Al}_{2} \mathrm{O}_{3} \mathrm{NPs}$ was higher than $0.2 \%$ concentration.

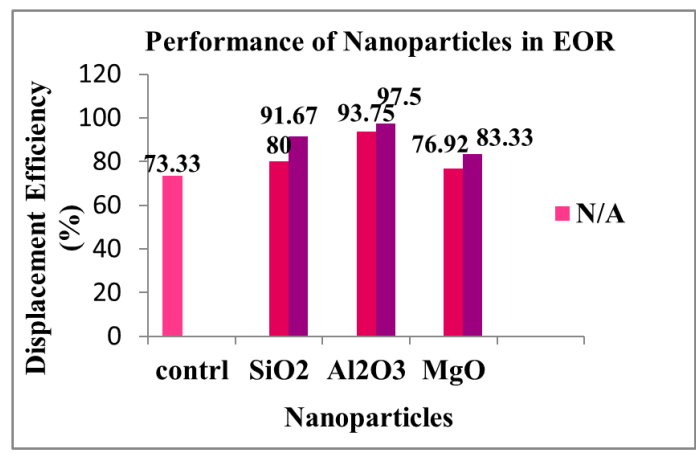

Figure 1. Displacement efficiency for different nanoparticles.

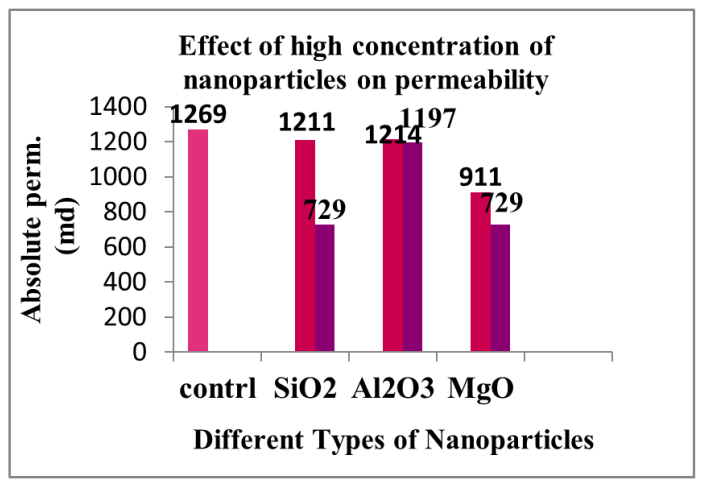

Figure 2. Permeability of nanoparticles at different concentration.
From figure 2, it shows that, aluminum oxide, magnesium oxide and silicon oxide nanoparticles dispersed in brine; all gave rise to permeability problems caused by pore space blockage. The permeability value of each nanofluid is lower than that obtained without the use of nanoparticles. Magnesium oxide result to highest reduction in permeability of the reservoir rock.

Figure 3 shows that, after EOR, magnesium oxide gave the least recovery amongst the other nanoparticles; this could be as a result of pore blockage. Aluminum oxide again gave the highest result. Aluminum oxide again has been reported to reduce oil viscosity while silicon oxide has been reported for its ability to change rock wettability. From the figure, increase in nanoparticle concentration, decreases the permeability of the reservoir rock.

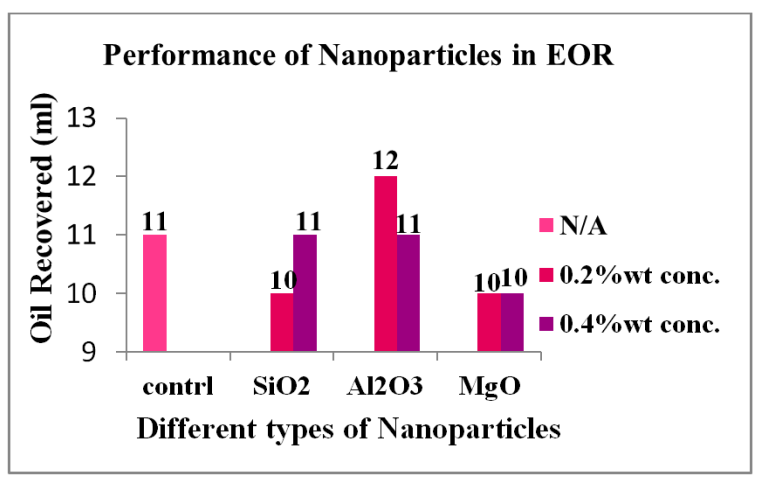

Figure 3. Oil recovery after EOR at different concentration.

In economic analysis, pore volume and incremental oil recovered were considered in scaling up the data. The values for pore volume and incremental oil displacement were shown in table 4.

Table 4. Sand-pack properties.

\begin{tabular}{llllll}
\hline Nano-particle & Pore vol $\left(\mathbf{c m}^{\mathbf{3}}\right)$ & OOIP $(\mathbf{m l})$ & $\begin{array}{l}\text { Oil disp. Before EOR } \\
(\mathbf{m l})\end{array}$ & $\begin{array}{l}\text { Cum. Oil disp. After } \\
\text { EOR }(\mathbf{m l})\end{array}$ & $\begin{array}{l}\text { Incremental oil disp. } \\
(\mathbf{m l})\end{array}$ \\
\hline contrl & 26.75 & 15 & 11 & $\mathrm{~N} / \mathrm{A}$ & $\mathrm{N} / \mathrm{A}$ \\
$\mathrm{SiO}_{2}$ & 26.26 & 12.5 & 9.166 & 10 & 0.834 \\
& 26.75 & 12 & 8.800 & 11 & 2.2 \\
$\mathrm{Al}_{2} \mathrm{O}_{3}$ & 26.75 & 12.8 & 9.386 & 12 & 2.614 \\
& 26.75 & 12 & 8.800 & 11.7 & 2.9 \\
$\mathrm{MgO}$ & 25.08 & 13 & 9.533 & 10 & 0.467 \\
& 25.28 & 12 & 8.800 & 10 & 1.2 \\
\hline
\end{tabular}


The scale up data is presented in table 5 shown below and they were scaled as $1 \mathrm{~cm}^{3}=1 \mathrm{ml}=500 \mathrm{bbl}$.

Table 5. Scale-up data for economic analysis.

\begin{tabular}{lll}
\hline Nano-particles & Pore volume (bbl) & Incremental oil recovered (bbl) \\
\hline control & 13375 & N/A \\
$\mathrm{SiO}_{2}$ & 13130 & 417 \\
& 13375 & 1100 \\
$\mathrm{Al}_{2} \mathrm{O}_{3}$ & 13375 & 1307 \\
& 13375 & 1450 \\
$\mathrm{MgO}$ & 12540 & 233.5 \\
& 12640 & 600 \\
\hline
\end{tabular}

Also table 6 shown below is the average price of the nanoparticles and they were gotten from Alibaba.com catalog survey.

Table 6. Price per barrel of nanofluid.

\begin{tabular}{ll}
\hline Nanoparticles & Price (dollar/lb) \\
\hline $\mathrm{SiO}_{2}$ & 4.545 \\
$\mathrm{Al}_{2} \mathrm{O}_{3}$ & 4.545 \\
$\mathrm{MgO}$ & 59.091 \\
\hline
\end{tabular}

The cost calculation formula is given as;

$$
\text { Nanoparticle concentration } \times \text { density of the brine }\left(\frac{\mathrm{lb}}{\mathrm{bbl}}\right) \times \text { NP price }\left(\frac{\text { dollar }}{\mathrm{bbl}}\right) \times 1 \mathrm{bbl}
$$

Density of the brine used for this experiment was $1.0167 \mathrm{~g} / \mathrm{cm}^{3}$

Conversion factor for density of brine to $\mathrm{lb} / \mathrm{bbl}$ is given as;

$$
1 \frac{\mathrm{g}}{\mathrm{cm}^{3}}=8.3454 \frac{\mathrm{lb}}{\text { US gal }} ; 1 \mathrm{bbl}=42 \text { US gal }
$$

Therefore density of brine is given as:

$$
1.0167 \frac{\mathrm{g}}{\mathrm{cm}^{3}} \times 8.3454 \frac{\mathrm{lb}}{\text { US gal }} \times \frac{\mathrm{cm}^{3}}{\mathrm{~g}} \times 42 \frac{\text { US gal }}{\mathrm{bbl}}=356.3603 \frac{\mathrm{lb}}{\mathrm{bbl}} .
$$

Table 8 shows the cost of $1 \mathrm{bbl}$ of preparation of nanofluid.

The cost of $1 \mathrm{bbl}$ of $0.2 \% \mathrm{wt}$. silicon oxide nanofluid is:

$$
\frac{0.2}{100} \times 356.3603 \frac{\mathrm{lb}}{\mathrm{bbl}} \times 4.545 \frac{\$}{\mathrm{lb}} \times 1 \mathrm{bbl}=\$ 3.2393
$$

The cost of $1 \mathrm{bbl}$ of $0.4 \% \mathrm{wt}$. silicon oxide nanofluid is:

$$
\frac{0.4}{100} \times 356.3603 \frac{\mathrm{lb}}{\mathrm{bbl}} \times 4.545 \frac{\$}{\mathrm{lb}} \times 1 \mathrm{bbl}=\$ 6.4786
$$

The cost of $1 \mathrm{bbl}$ of $0.2 \% \mathrm{wt}$. aluminum oxide nanofluid is:

$$
\frac{0.2}{100} \times 356.3603 \frac{\mathrm{lb}}{\mathrm{bbl}} \times 4.545 \frac{\$}{\mathrm{lb}} \times 1 \mathrm{bbl}=\$ 3.2393
$$

The cost of $1 \mathrm{bbl}$ of $0.4 \% \mathrm{w}$. aluminum oxide nanofluid is:

$$
\frac{0.4}{100} \times 356.3603 \frac{\mathrm{lb}}{\mathrm{bbl}} \times 4.545 \frac{\$}{\mathrm{lb}} \times 1 \mathrm{bbl}=\$ 6.4786
$$

The cost of $1 \mathrm{bbl}$ of $0.2 \%$ wt. magnesium oxide nanofluid is:

$$
\frac{0.2}{100} \times 356.3603 \frac{\mathrm{lb}}{\mathrm{bbl}} \times 59.091 \frac{\$}{\mathrm{lb}} \times 1 \mathrm{bbl}=\$ 42.1154
$$

The cost of $1 \mathrm{bbl}$ of $0.4 \%$ wt. magnesium oxide nanofluid is:

$$
\frac{0.4}{100} \times 356.3603 \frac{\mathrm{lb}}{\mathrm{bbl}} \times 59.091 \frac{\$}{\mathrm{lb}} \times 1 \mathrm{bbl}=\$ 84.2307
$$

From experience, it is normal to inject about 0.5 pore volume of the enhanced oil recovery agent prepared with brine, less may lead to inefficient sweep of the oil while more may leads to wastage of enhanced oil recovery agent. The total cost of producing each nanofluid is shown below. 
Table 7. Total cost of producing nanofuid.

\begin{tabular}{llll}
\hline Nano-particles & $\mathbf{0 . 5 p o r e ~ v o l . , ~ b b l ~}$ & $\mathbf{\$} / \mathbf{b b l}$ & Total cost of production (bbl $\times$ \$/bbl) \\
\hline $\mathrm{SiO}_{2}$ & 6565 & 3.2393 & 21266 \\
$\mathrm{Al}_{2} \mathrm{O}_{3}$ & 6687.5 & 3.2393 & 21663 \\
$\mathrm{MgO}$ & 6270 & 42.1154 & 264064 \\
$\mathrm{SiO}_{2}$ & 6687.5 & 6.4786 & 43326 \\
$\mathrm{Al}_{2} \mathrm{O}_{3}$ & 6687.5 & 6.4786 & 43326 \\
$\mathrm{MgO}$ & 6320 & 84.2307 & 532338 \\
\hline
\end{tabular}

Table 8 shows 0.5 pore volume of each nanoparticles at different concentration. The revenue generated based on the average cost of the crude oil $(\$ 55 / \mathrm{bbl})$ and the total cost of production is shown in the same table.

Table 8. Profit/loss and revenue data.

\begin{tabular}{lllll}
\hline Nano-particles & $\mathbf{0 . 5 p o r e ~ v o l . , ~ b b l ~}$ & Incremental oil disp. (bbl) & Revenue (bbl $\times$ \$55/bbl) & Profit/loss (\$) \\
\hline $\mathrm{SiO}_{2}$ & 6565 & 417 & 22935 & 1669 \\
$\mathrm{Al}_{2} \mathrm{O}_{3}$ & 6687.5 & 1307 & 71885 & \\
$\mathrm{MgO}$ & 6270 & 233.5 & 12842.5 & $(251221)$ \\
$\mathrm{SiO}_{2}$ & 6687.5 & 1100 & 60500 & 17174 \\
$\mathrm{Al}_{2} \mathrm{O}_{3}$ & 6687.5 & 1450 & 79750 & 36424 \\
$\mathrm{MgO}$ & 6320 & 600 & 33000 & $(499338)$ \\
\hline
\end{tabular}

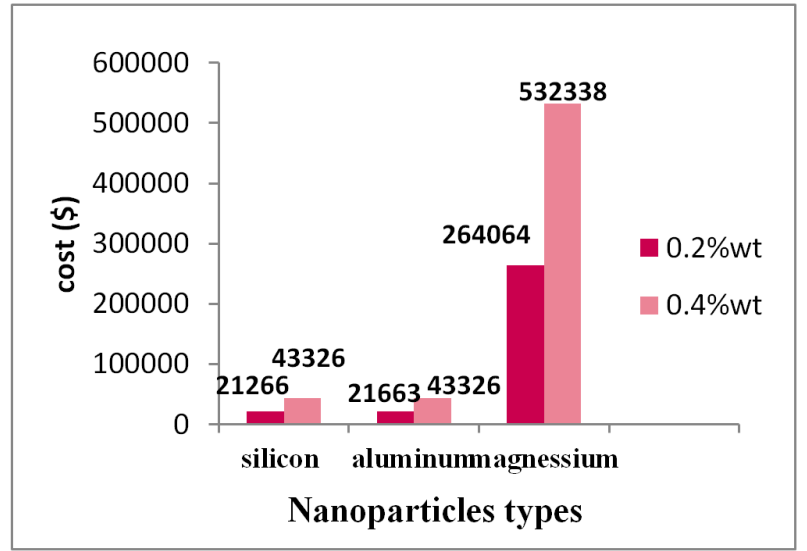

Figure 4. Total Cost of Nanofluid Preparation.

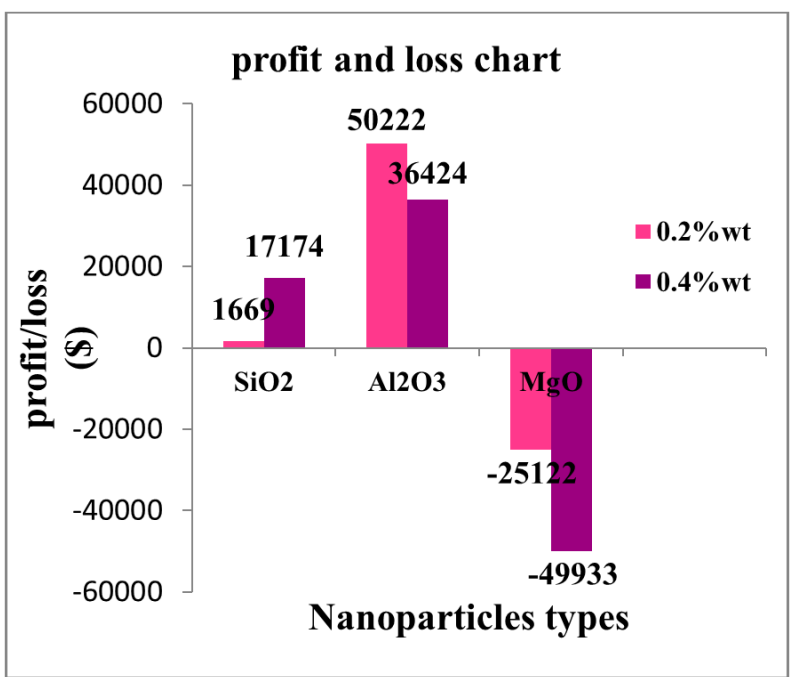

Figure 5. Profit and Loss Data for Different nanoparticles.

Figure 4 shows that, increase in nanoparticles concentration increases the total cost of preparing the nanofluid. As you can see from figures 4 and 5, it shows that at $0.2 \%$ wt, only aluminum oxide $\left(\mathrm{Al}_{2} \mathrm{O}_{3}\right)$ nanofluid is economical feasible at the current average crude oil price, but even though aluminum oxide nanofluid gave the highest oil displacement at $0.4 \% \mathrm{wt}$, the profit recovered at that concentration is less than the total cost of preparation which shows that it is not economical feasible at the current average crude oil price at that concentration, but increase in oil price and decrease in price of aluminum oxide nanofluid may make it to be economical feasible.

\section{Observations}

When oil was injected to displace the brine during control experiment, it greatly displaced the brine because it is more viscous than brine but brine couldn't displace the oil effectively when it was injected due to high viscosity of the crude oil. It took time to achieve a stable differential pressure across the sand-pack during control experiment. This was as a result of the nature of the sand-pack during its preparation. Aluminum oxidenanoparticle was capable to greatly reduce the viscosity of the oil which made it to be more effective in oil recovery than other nanoparticles. It gave best results. Nano-particles improve oil recovery. It took time to achieve a stable differential pressure across the sand-pack during control experiment. This was as a result of the nature of the sand-pack during its preparation. Brine effluent from the use of magnesium oxide nanoparticle was very clean. Silicon oxidenanoparticle had least effect on permeability reduction compared to other nanoparticles.

\section{Conclusions}

i. To compare the efficiency of displacing fluid, second experiments gave better results than the first experiments. This is as a result of the presence of nanoparticles in brine used for the second experiments to displace the oil.

ii. The three nanoparticles used were good but aluminum oxide $\left(\mathrm{Al}_{2} \mathrm{O}_{3}\right)$ gave the best result of all. It gave the 
maximum displacement efficiency of $93.75 \%$ at $0.2 \%$ concentration $97.50 \%$ at $0.4 \%$ concentration which means increase in nanoparticles concentration increases the displacement efficiency.

iii. Increase in nanoparticles concentration, increases the recovery factor but also decrease the permeability of reservoir rock and also increase in nanoparticles concentration, increases the cost of nanofluid preparation.

iv. Recovery from the use of magnesium oxide $(\mathrm{MgO})$ is always less compared with the other nanoparticles used.

v. Silicon oxide improves oil recovery through change in sand-pack wettability while dispersed in brine.

vi. All the nanoparticles results to reduction in permeability of the sand-pack butmagnesium oxide gave the highest reduction.

vii. Most of the nanoparticles can cause negative effect on oil recovery such as increase in its concentration decrease the permeability of the rock caused by pore blockage. When using the nanoparticles dispersed in brine for enhanced oil recovery process, caution should be taken.

\section{Recommendation}

i. To carry out any laboratory experiment onenhanced oil recovery, core plug should be used for perfect result instead of sand-pack.

ii. From all the results, aluminum oxide $\left(\mathrm{Al}_{2} \mathrm{O}_{3}\right)$ is a goodenhanced oil recovery agent and can be used to greatly improve oil recovery while dispersed in brine.

iii. Oil production is not advisable to start at high flow rate because it will damage the sand-pack and leads to fine migration (sand) which may block the flow channels. During any production, it is recommended to start from a low flow rate and gradually increase the flow rate by steps.

iv. To conduct anyenhanced oil recovery experiment, right nanoparticle concentration should be use to avoid pore blockage which will result to permeability reduction.

\section{Acknowledgements}

i. Laser Engineering and Resources Consultants Limited, Kilometer 5 East-West Road Rumuodara, Port Harcourt, Rivers State, Nigeria.

ii. Department of Petroleum Engineering, Federal University of Technology Owerri, Imo State, Nigeria.

\section{References}

[1] Jagai A. Ali, Kamal Kolo, Abbas Khaksar Manshad, Amir. H. Mohammadi (26 ${ }^{\text {th }}$ September, 2018), "Recent Advance in Application of Nanotechnology in Chemical EOR": Effects of NPs on Wettability Alteration, Interfacial Tension Reduction and Flooding. Egyptian Journal of Petroleum. Pp. 6-9.
[2] A. Agi, R. Junin, and A. Gbadamosi (19 ${ }^{\text {th }}$ May, 2018), "Mechanism Governing Nanoparticles Flow Behavior in Porous Media": Insight for EOR Applications. Pp. 3, 4, 5 \& 8.

[3] N. A Ogolo, O. A. Okafuyi and M. O. Onyekonwu (April 2012), "EOR Using Nanoparticles" Petroleum Technology Development Fund Research Group, Institute Of Petroleum Studies, University of Port Harcourt, Rivers State, Nigeria. Pp $2-4$.

[4] A. I. El-Diasty and A. M. Aly (September, 2015), "Understanding the Mechanisms of NPs Application in Enhanced Oil Recovery". Presented at the SPE North Africa Technical Conference and Exhibition held in Cairo, Egypt, 14 $-16^{\text {th }}$ September, 2015. Pp. 3-5.

[5] N. A. Ogolo, O. A. Olafuyi and M. O. Onyekonwu (June, 2012), "Effects of Nanoparticles on Migrating Fine Formation". Presented at the SPE International Oilfield Nanotechnology Conference held in Noordwijk, The Netherlands, 12-14 June, 2012.

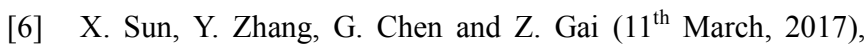
"Application of Nanoparticles in EOR": A Critical Review of Recent Process. College of Petroleum Engineering, China University of petroleum (East China). Pp. 1, 2, 3, 4, 5-8.

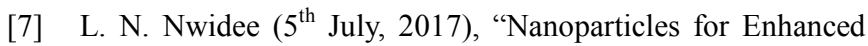
Oil Recovery Processes". Pp. 26, 42-46, 48-55.

[8] C. Negin, S. Ali, and Q. Xie (10 $0^{\text {th }}$ October, 2016), "Applications of Nanotechnology for EOR". Pp. 2, 4.

[9] K. Li, D. Wang and S. Jiang (30 $0^{\text {th }}$ October, 2018), "Review on Enhanced Oil Recovery by Nanofluid”. Pp. 2-3, 6-7 \& 22.

[10] L. R. Arif (May, 2015), "Investigation of NPs Dispersion in Porous Media". Pp. 10-12.

[11] L. N. Nwidee (June, 2017), "NPs for EOR Process".

[12] C. Uzoho, M. O. Onyekonwu, and O. Akaranta (July, 2019), "Chemical Flooding EOR Using Local Alkaline-SurfactantPolymer (ASP)". University of Port Harcourt Rivers State, Nigeria. Pp. 2-3.

[13] C. Uzoho, M. O. Onyekonwu, and O. Akaranta (May, 2019), "Characterization for Local Materials for EOR". University of Port Harcourt Rivers State, Nigeria. Pp. 2-3.

[14] W. Wang, B. Yuan, Y. Su, K. Wang, M. Jiang, R. G. M. Moghanloo, Z. Rui, "NPs Adsorption, Straining and Detachment Behavior and its Effects on Permeability of Berea Cores". Paper presented at the SPE Annual Technical Conference and Exhibition held in Dubai, UAE, 26-28 September, 2016. Pp. 2.

[15] A. A. M. Yassin, U. Teknologi, (February 1988), "EOR in Malaysia". Paper presented at the $7^{\text {th }}$ offshore South East Asia Conference held in Singapore, 2-5 February, 1988. Pp 2.

[16] Federico Caldelas, Michael J. Murphy, Chun Huh and Steven L. Bryant (March, 2011), "Factors Governing Distance of NPs Propagation in Porous Media".

[17] C. Uzoho, M. O Onyekonwu and O. Akaranta (August, 2016), "Alkaline Surfactant Flooding in Niger Delta". Paper presented at the SPE Nigeria Annual International Conference and Exhibition held in Lagos, Nigeria, 2-4 August, 2016. Pp 1, 2. 